\title{
Acid-base balance in acute ethylene glycol poisoning in rats treated with fomepizole
}

\author{
Jędrzej Przystanowicz, Barbara Zielińska-Psuja, Joanna Kowalówka-Zawieja, Karina Sommerfeld
}

Department of Toxicology, Poznan University of Medical Sciences, Poland

\begin{abstract}
Introduction. Ethylene glycol (EG) is relatively nontoxic but undergoes a multi-step oxidation to toxic metabolites, aldehydes and acids. The accumulation of organic acids, mainly glycolates, leads to the development of profound, life-threatening metabolic acidosis. A key therapy is an antidotal treatment with fomepizole (4-MP), the inhibitor of the first step of EG biotransformation enzyme, alcohol dehydrogenase.

Aim. The aim of the study was to demonstrate the efficacy of fomepizole in the prevention of acid-base balance disorders in acute ethylene glycol poisonings in rats.

Material and methods. Adult male Wistar rats were given EG (p.o.) with single (i.p.) or multiple (p.o.) doses of 4-MP (EG 3830 and $5745 \mathrm{mg} / \mathrm{kg}$, respectively, 4-MP in single dose of $10 \mathrm{mg} / \mathrm{kg}$ or $15 \mathrm{mg} / \mathrm{kg}$ followed by $10 \mathrm{mg} / \mathrm{kg}$ every 12 hours). Blood gas analysis was performed and blood pH, bicarbonate concentration and base excess were evaluated.

Results and conclusions. The single dose of 4-MP was effective in preventing a decrease in blood pH, bicarbonate concentration and base excess during the entire experimental period ( $\mathrm{pH} 7.35$ vs 7.21 at hour 12, bicarbonate concentration 27.2 vs $18.3 \mathrm{mmol} / \mathrm{dm}^{3}$ at hour 8 , base excess $1.8 \mathrm{vs}-8.2 \mathrm{mmol} / \mathrm{dm}^{3}$ at hour 18 ). The multiple administration of 4-MP started 2 hours after EG poisoning resulted in rapid restoration of proper values of acid-base balance parameters. Fomepizole is highly efficacious in restraining the acid-base balance disorders which are concomitant with acute ethylene glycol poisonings.
\end{abstract}

Key words: ethylene glycol, fomepizole, acid-base balance, acute poisoning, rats.

\section{Introduction}

Acute ethylene glycol (EG) poisoning is most frequently a result of ingestion of its solutions (antifreeze, coolants and de-icing fluids), which may be accidental or, in humans, intentional - suicidal or ingested as a substitute for ethanol [1, 2]. Upon absorption to blood EG is relatively nontoxic and in the first stage of poisoning it causes inebriating effects similar to those of ethanol. EG is converted by alcohol dehydrogenase (ADH) and subsequently by other enzymes to highly toxic metabolites, aldehydes and acids [2, 3, 4]. The accumulation of organic acids, mainly glycolates, leads to the development of metabolic acidosis [1, 2, 5]. The reactions of EG oxidation are accompanied by an increase in the ratio of reduced to oxidized form of the nicotinamide adenine dinucleotide, and, consequently, by lactate accumulation and development of lactic acidosis [1, 2].

The development of acid-base balance disorders is typical of the second stage of EG poisoning, which causes multi-organ injury, cardiac dysrhythmia, myocardial depression, congestive heart failure, pulmonary oedema and adult respiratory distress syndrome. Untreated acid-base balance disorders are often fatal $[1,2]$. The third stage of poisoning is characterized by acute renal failure due to the accumulation of EG metabolite crystals, calcium oxalate, and the direct cytotoxic effect of other EG metabolites $[2,4]$.

A first-line therapy in EG acute poisoning is an antidotal treatment with ADH inhibitor, ethanol or fomepizole, which enables excretion of the unchanged EG 
with urine $[2,3]$. Fomepizole (4-methylpyrazole, 4-MP) is a newer, more efficacious and safer antidote in poisonings caused by EG, methanol and other toxic alcohols $[2,3,6,7]$.

A review of available literature provides only limited information about the influence of the treatment with fomepizole on the acid-base status in acute ethylene glycol poisoning. These data come from studies conducted on small groups of animals, such as dogs or cats $[8,9]$. The aim our study was to demonstrate the efficacy of 4-MP in the prevention of acid-base balance disorders in acute ethylene glycol poisonings in rats.

\section{Material and methods}

Material

Ethylene glycol 99\%+ (Sigma-Aldrich) and 4-methyIpyrazole 99\% (Aldrich) were used in the experiment. Solutions were prepared with use of Aqua pro injectione and Natrium chloratum 0.9\% inj. (Baxter Polska).

\section{Animals}

Adult male Wistar rats weighing $280 \pm 20 \mathrm{~g}$ were purchased from the breeding farm of the Department of Toxicology, Poznan University of Medical Sciences, Poznań, Poland. The animals were fed with standard laboratory chow Labofeed $\mathrm{H}$ and were provided drinking water ad libitum. The room in which the animals were housed had standardized environmental temperature $\left(20 \pm 2^{\circ} \mathrm{C}\right)$, relative humidity (50-60\%) and 12-h photocycle. Food was withdrawn 12 hours prior the administration of xenobiotics and rats were starved during the whole experimental period in stage I. In stage II the food was returned 6 hours post-dosing. Water ad libitum was provided all the time.

Animals used in the study were treated in compliance with the recommendations from the Declaration of Helsinki. The experimental protocol was approved by the Local Ethical Committee for Experiments on Animals (permissions no. 3/2004 and 20/2009).

\section{Experimental design}

There were two separate stages of the study.

Stage I - the animals were divided into 4 groups: control group K1 receiving water, group G1 receiving ethylene glycol at a dose of $3830 \mathrm{mg} / \mathrm{kg}$ (p.o.), group M1 receiving fomepizole at a dose of $10 \mathrm{mg} / \mathrm{kg}$ (i.p.) and group GM1 receiving ethylene glycol at a dose of $3830 \mathrm{mg} / \mathrm{kg}$ (p.o.) together with fomepizole at a dose of $10 \mathrm{mg} / \mathrm{kg}$ (i.p.). Each of the groups consisted of 55 animals, 5 for each of 11 time points of the experiment.

The xenobiotics under study were administered once and simultaneously. The animals in control group $\mathrm{K} 1$ were given $3 \mathrm{~cm}^{3}$ of water by gavage and the animals in groups $\mathrm{G} 1$ and $\mathrm{GM} 1$ were given ethylene glycol by gavage as a $3 \mathrm{~cm}^{3}$ water solution. The animals in groups M1 and GM1 were given fomepizole intraperitoneally as a $0.5 \mathrm{~cm}^{3}$ solution in saline.

Stage II - the animals were divided into 3 groups: control group $\mathrm{K} 2$ receiving water, group $\mathrm{G} 2$ receiving ethylene glycol at a dose of $5745 \mathrm{mg} / \mathrm{kg}$ (p.o.) and group GM2 receiving ethylene glycol at a dose of $5745 \mathrm{mg} / \mathrm{kg}$ (p.o.) together with fomepizole at a loading dose of $15 \mathrm{mg} / \mathrm{kg}$ (p.o.) 2 hours after EG administration, followed by maintaining doses of $10 \mathrm{mg} / \mathrm{kg}$ (p.o.) every 12 hours. Each of the groups consisted of 105 animals, 7 for each of 15 time points of the experiment.

The animals in control group $\mathrm{K} 2$ were given $3 \mathrm{~cm}^{3}$ of water by gavage and the animals in groups $\mathrm{G} 2$ and GM2 were given ethylene glycol by gavage as a $3 \mathrm{~cm}^{3}$ water solution. The animals in the group GM2 were given fomepizole as a $1 \mathrm{~cm}^{3}$ water solution.

In both stages the animals were anesthetized with ketamine (Bioketan ${ }^{\circledR}$, Biowet, Poland, $100 \mathrm{mg} / \mathrm{kg}$, i.m.) after $0.5,1,2,4,6,8,12,18,24,36$ and 48 hours and additionally after $60,72,96$ and 120 hours in stage II. Blood was collected from the rat tail into heparinised capillary tubes.

\section{Blood gas analysis}

Blood gas analysis was conducted on Radiometer ABL 500 blood gas analyzer. The device was equipped with electrodes for $\mathrm{pH}$, oxygen tension and carbon dioxide tension measurements. On the basis of the results of determined parameters the analyzer calculated the bicarbonate concentration and base excess (BE).

\section{Statistical analysis}

The received results are presented as an arithmetic mean. All parameters were compared between the groups for each of the time points by one-way ANOVA with Tukey's post hoc test. The statistical analysis was made with GraphPad InStat ver. 3.06 for Windows (GraphPad Software). Values of $\mathrm{P}<0.05$ were considered significant. Data different from the values in the control group are marked with an asterisk $\left({ }^{*}\right)$ and data different from the values in the untreated groups poisoned with ethylene glycol are marked with a dagger (†). 


\section{Results}

Figures 1-3 show the results of blood gas analysis in stage I concerning blood $\mathrm{pH}$, bicarbonate concentration and $\mathrm{BE}$ after EG administration to the rats (3830 mg/kg, p.o.) and/or 4-MP (10 mg/kg, i.p.).

In control group $\mathrm{K} 1$ in $0.5-48$ hours blood $\mathrm{pH}$ ranged from 7.35 to 7.40 , bicarbonate concentration $29.6-33.3 \mathrm{mmol} / \mathrm{dm}^{3}$ and base excess $4.7-8.1$ $\mathrm{mmol} / \mathrm{dm}^{3}$. In group $\mathrm{G} 1$ blood $\mathrm{pH}$ decreased significantly after EG administration as early as 1 hour of the experiment ( $\mathrm{pH} 7.26)$, reaching the minimum after 12 hours ( $\mathrm{pH}$ 7.21). After 48 hours blood $\mathrm{pH}$ returned to the reference values ( $\mathrm{pH}$ 7.36). Similarly, the bicarbonate concentration was decreased, reaching the minimum $\left(18.3 \mathrm{mmol} / \mathrm{dm}^{3}\right)$ after 8 hours of the experiment. Normal values were found again after 36 and 48 hours post-dosing (24.9 and $32.3 \mathrm{mmol} / \mathrm{dm}^{3}$, respectively). $\mathrm{BE}$ reflected measured bicarbonate concentrations and reached $-7.9 \mathrm{mmol} / \mathrm{dm}^{3}$ after 6 hours and a minimum of $-8.2 \mathrm{mmol} / \mathrm{dm}^{3} 18$ hours after EG administration. At the end of the experiment $\mathrm{BE}$ ranged between the reference values $\left(-1.2 \mathrm{mmol} / \mathrm{dm}^{3}\right.$ after 36 hours and $6.9 \mathrm{mmol} / \mathrm{dm}^{3}$ after 48 hours).

In groups M1 and GM1 blood pH was slightly lower than in the control group, with a significant decrease after 2 and 6-18 hours in group GM1. At all time points the blood $\mathrm{pH}$ values did not fall below 7.31. The bicarbonate concentration (minimum $26.0 \mathrm{mmol} / \mathrm{dm}^{3}$ ) and $\mathrm{BE}$ (minimum $0.6 \mathrm{mmol} / \mathrm{dm}^{3}$ ) behaved similarly in these groups.

Figures 4-6 show the results of blood gas analysis in stage II concerning blood $\mathrm{pH}$, bicarbonate concentration and $\mathrm{BE}$ after $\mathrm{EG}$ administration to the rats (5745 mg/kg, p.o.), single and combined with 4-MP at the loading dose of $15 \mathrm{mg} / \mathrm{kg}$ (p.o.) 2 hours after EG administration followed by maintaining doses of $10 \mathrm{mg} / \mathrm{kg}$ (p.o.) every 12 hours.

In control group K2 in $0.5-120$ hours blood pH was ranged from 7.34 to 7.38 , bicarbonate concentration $27.1-32.9 \mathrm{mmol} / \mathrm{dm}^{3}$ and $\mathrm{BE} 3.5-6.5 \mathrm{mmol} / \mathrm{dm}^{3}$. In group $\mathrm{G} 2$ blood $\mathrm{pH}$ after the administration of ethylene glycol was significantly lower, starting from 0.5 hour ( $\mathrm{pH} 7.28$ ) to 36 hours, reaching the minimum 4 hours post-dosing ( $\mathrm{pH} 7.20)$.

After 48 hours of the experiment blood pH almost returned to reference values $(\mathrm{pH}$ 7.33). The bicarbonate concentration was decreased analogically, reaching the minimum $\left(19.3 \mathrm{mmol} / \mathrm{dm}^{3}\right)$ after 4 hours. Normal values were recovered after 24 hours of poisoning $\left(31.2 \mathrm{mmol} / \mathrm{dm}^{3}\right)$. The measured base excess was minimal $\left(-8.9 \mathrm{mmol} / \mathrm{dm}^{3}\right) 4$ hours post-dosing and after 24 hours it returned to the reference values $\left(3.7 \mathrm{mmol} / \mathrm{dm}^{3}\right)$.

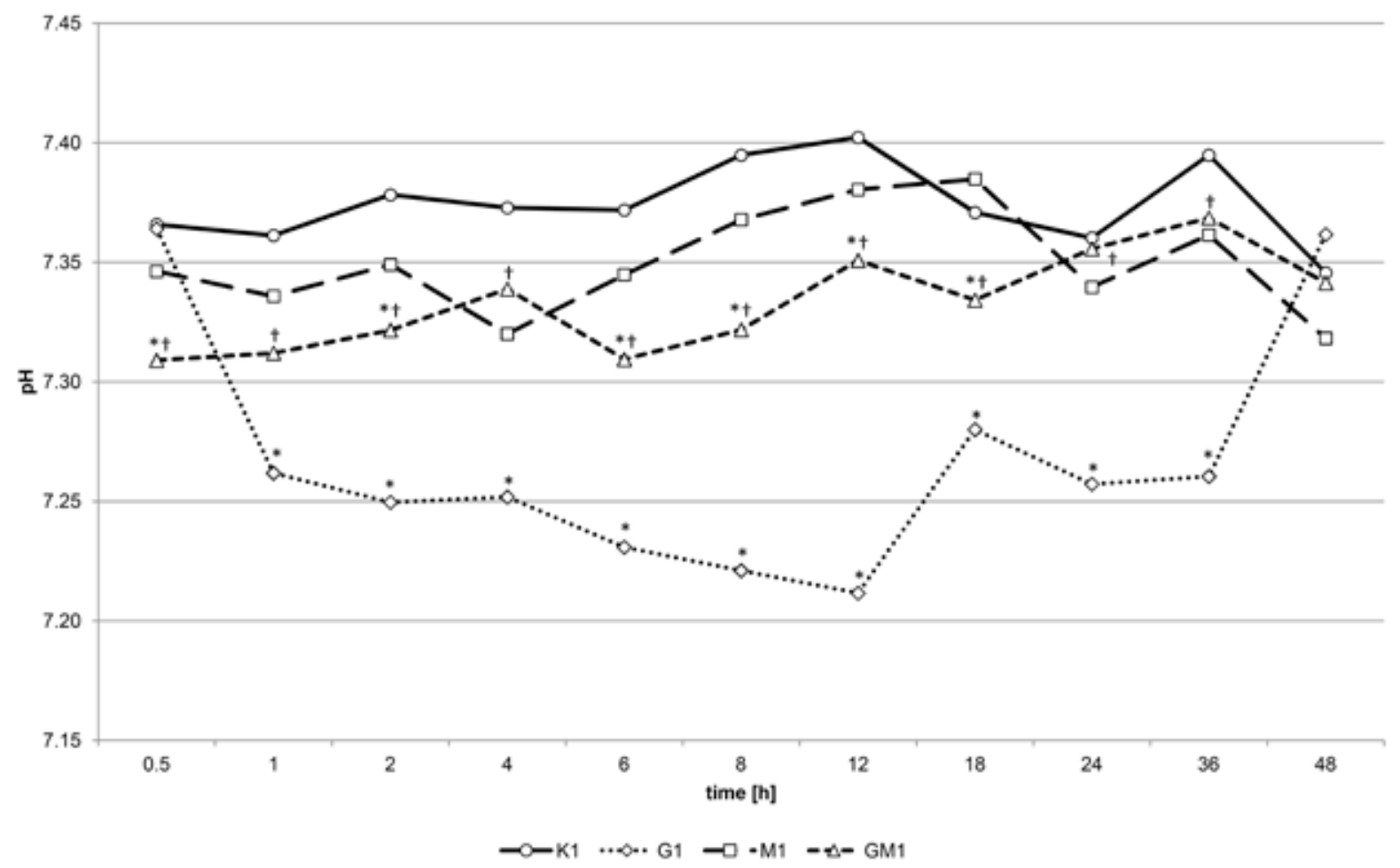

Figure 1. Blood $\mathrm{pH}$ in rats - stage I 


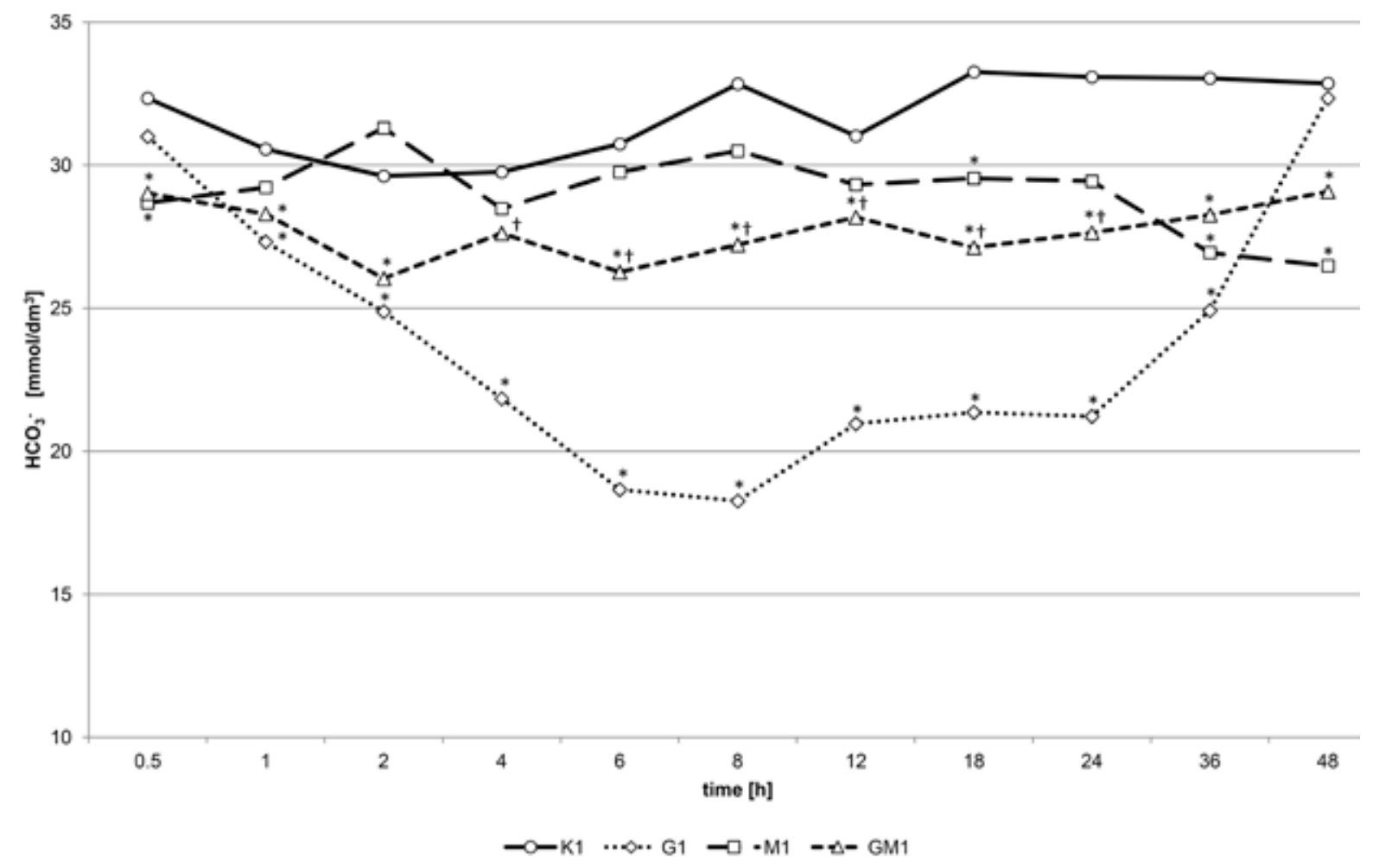

Figure 2. Blood bicarbonate concentration in rats - stage I

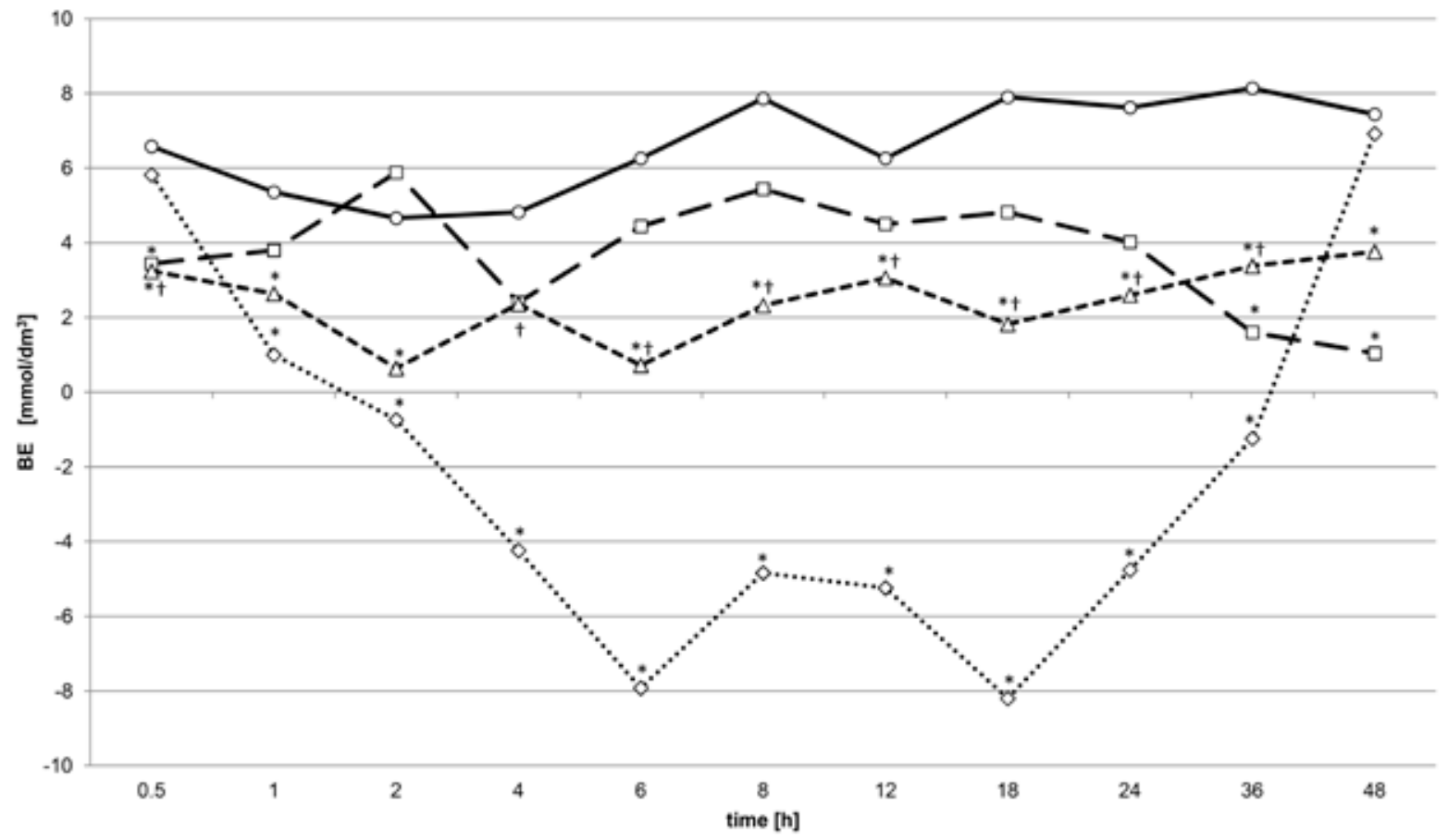

$\multimap-\mathrm{K} 1 \quad \cdots \infty \cdot \mathrm{G} 1 \rightarrow \cdot \mathrm{M} 1 \quad \leadsto-\mathrm{GM} 1$

Figure 3. Blood base excess in rats - stage I 


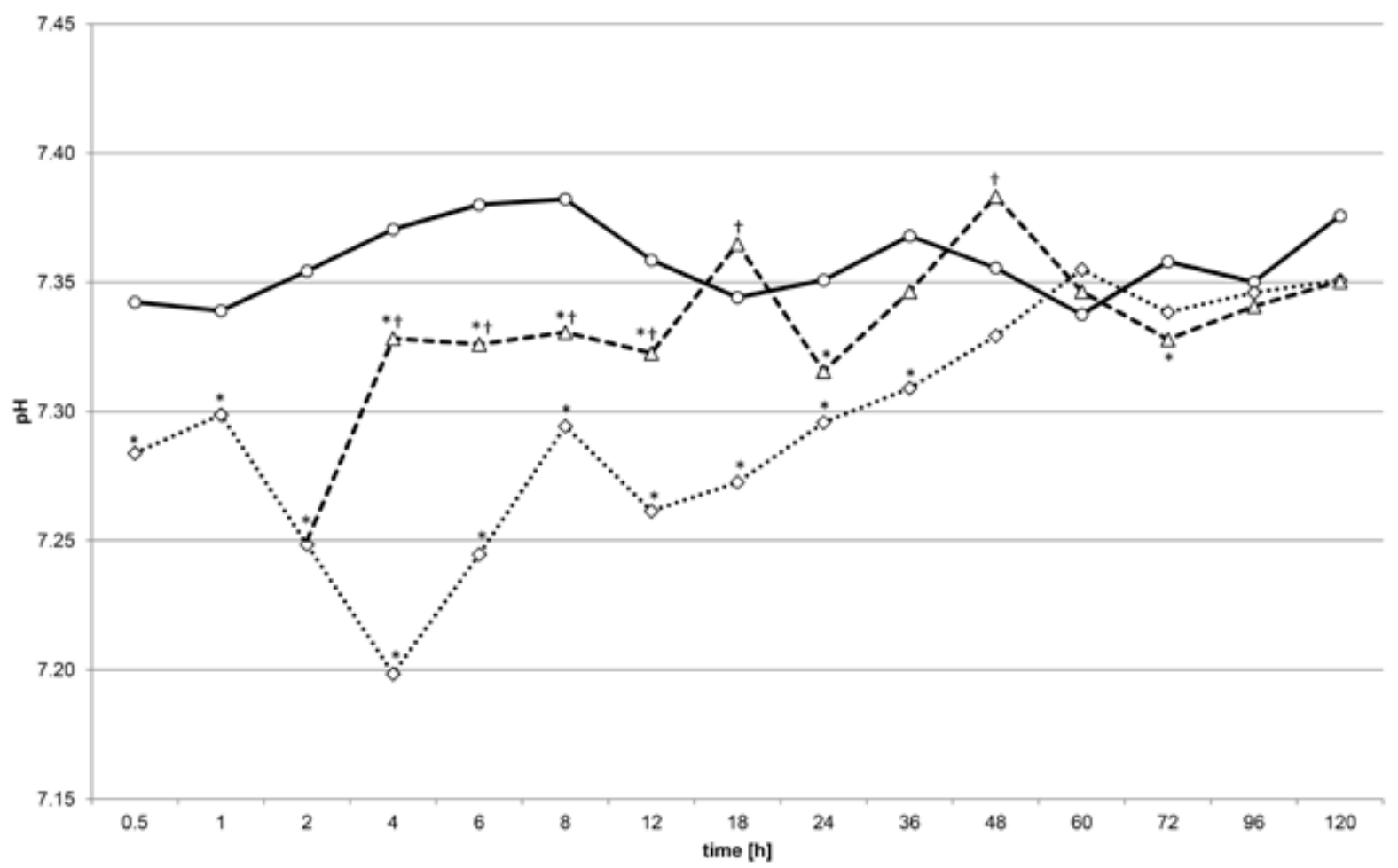

$\longrightarrow-K_{2} \quad \cdots \diamond \cdot G 2 \quad-\bowtie-G M 2$

Figure 4. Blood pH in rats - stage II

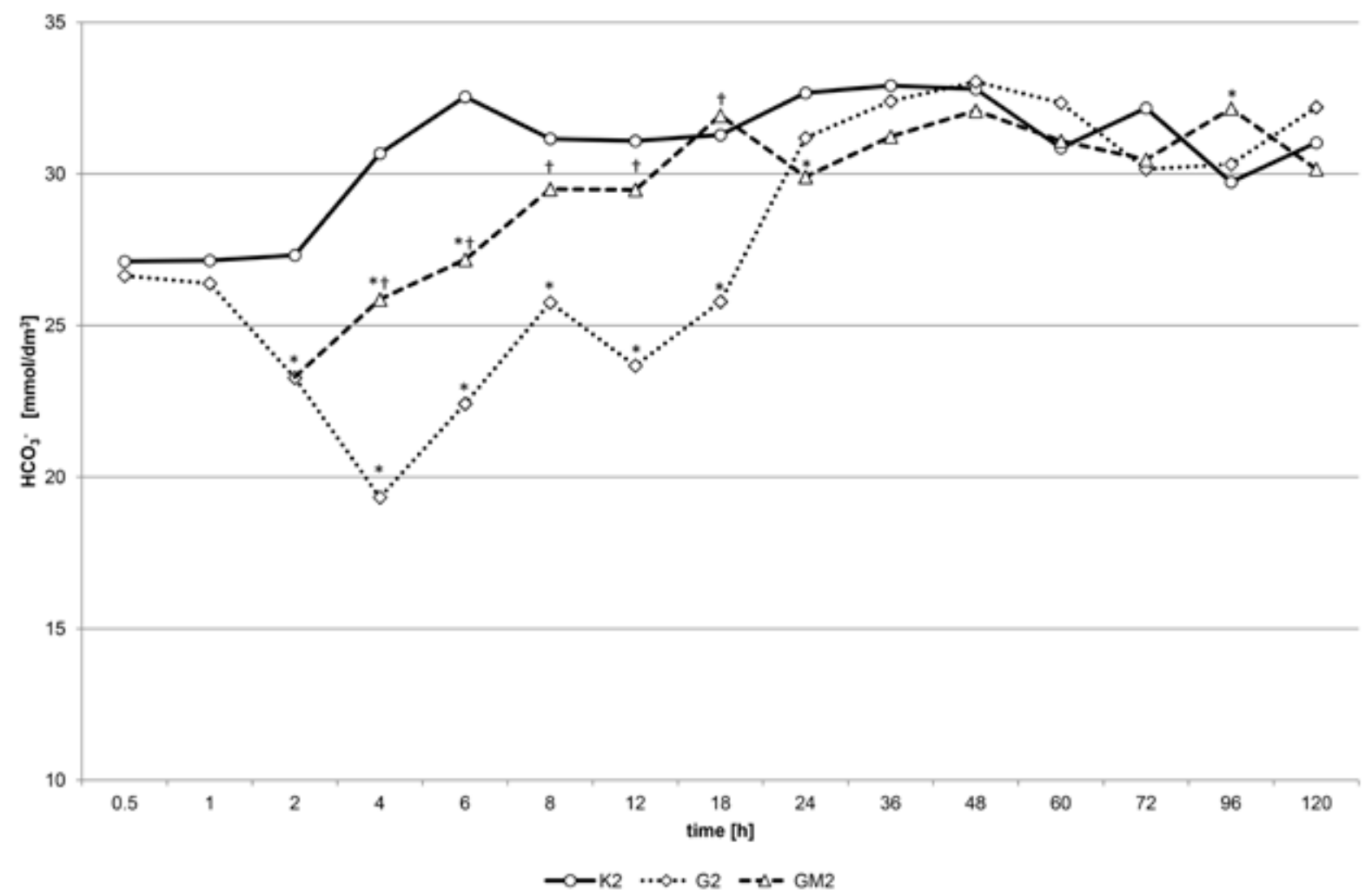

Figure 5. Blood bicarbonate concentration in rats - stage II 


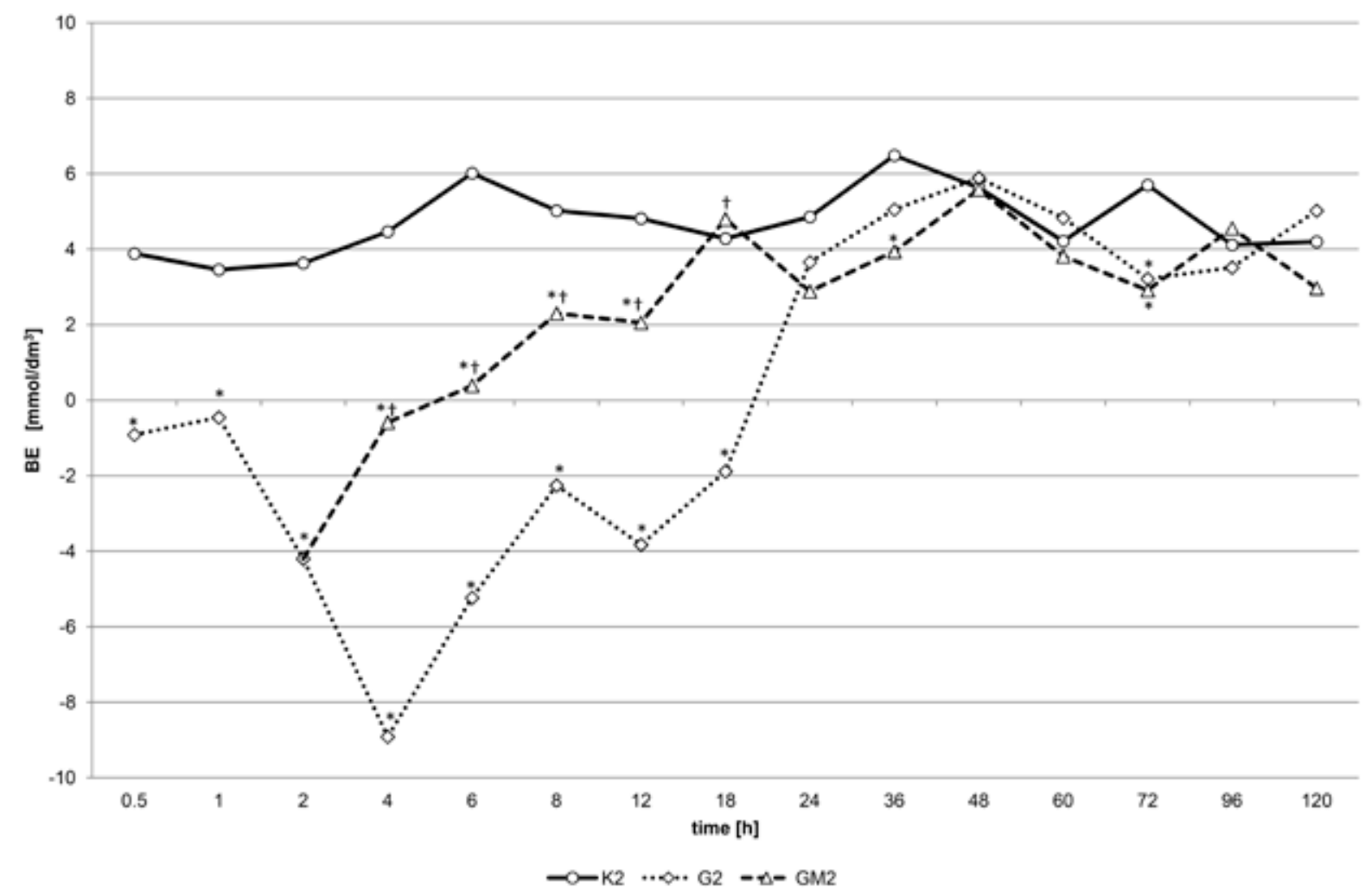

Figure 6. Blood base excess in rats - stage II

The administration of 4-MP at a loading dose 2 hours after EG poisoning in group GM2 resulted in a statistically significant increase in all of the evaluated parameters $\left(\mathrm{pH} 7.33\right.$ vs 7.20, $\mathrm{HCO}_{3} 25.9$ vs $19.3 \mathrm{mmol} / \mathrm{dm}^{3}, \mathrm{BE}-0.6 \mathrm{vs}-8.9 \mathrm{mmol} / \mathrm{dm}^{3}$ ) as early as 2 hours later, i.e., 4 hours after the administration of EG, as compared to untreated group G2. After 18 hours of the experiment the values of acid-base balance parameters in group GM2 did not differ significantly from the values in control group $\mathrm{K} 2$, except the time point of 24 hours, at which they temporarily decreased slightly $\left(\mathrm{pH} 7.32, \mathrm{HCO}_{3}{ }^{-} 29.9 \mathrm{mmol} / \mathrm{dm}^{3}\right.$, BE $\left.2.9 \mathrm{mmol} / \mathrm{dm}^{3}\right)$.

\section{Discussion}

The development of metabolic acidosis is typical of ethylene glycol poisoning and is associated with EG biotransformation to acidic metabolites, above all with the production and accumulation of glycolates, and to a lesser extent - glyoxylates and oxalates $[2,10]$. During the multi-step reaction of EG oxidation the nicotinamide adenine dinucleotide (NAD) is depleted, which results in the increase in $\mathrm{NADH}+\mathrm{H}^{+} / \mathrm{NAD}^{+}$ratio and, subsequently, in the increase in lactate/pyruvate ratio, contributing to the development of lactic acidosis [11].
The bicarbonate buffering system, the main buffering system of the extracellular fluid, is the first line of defence against the arising acidic EG metabolites and $\mathrm{pH}$ disorders developing under their influence $[12,13]$. The biotransformation of glycolates to glycine, lactate and carbon dioxide is also responsible for the decrease in bicarbonate concentration [10, 14]. The development of acidosis is facilitated by the disturbed respiratory compensation of metabolic acidosis due to respiratory depression and by the progression of renal failure $[10,12]$.

In humans, EG acute poisoning with a decrease in bicarbonate concentration below $9 \mathrm{mmol} / \mathrm{dm}^{3}$ considerably increases the risk of death and a drop below $5 \mathrm{mmol} / \mathrm{dm}^{3}$ causes the risk of death to be 3 times more likely than survival. The risk of death is similarly increased when pH falls below 7.0 [4]. The drop of blood pH below 6.8 was demonstrated to result in protein denaturation, inhibition of enzymes and it may lead to death [15]. The lowest values of $\mathrm{pH}$ and bicarbonate concentrations mentioned in the literature in patients who had survived acute EG poisoning were 6.46 [14] and $0.5 \mathrm{mmol} / \mathrm{dm}^{3}$ [16], respectively.

To assess the acid-base balance in untreated and treated acute ethylene glycol poisoning in rats $\mathrm{pH}$, 
bicarbonate concentration and base excess in capillary blood were measured.

Blood $\mathrm{pH}$ in control groups $\mathrm{K} 1$ and $\mathrm{K} 2$ ranged from 7.34 to 7.40 during the whole experiment and almost coincided with the reference values in humans which vary from 7.36 to 7.44 [17]. The bicarbonate concentration in these groups was $27.1-33.3 \mathrm{mmol} / \mathrm{dm}^{3}$, so it was higher than so-called standard bicarbonate concentration - 21-25 mmol/dm $\mathrm{dm}^{3}$ [17]. Base excess in animals from control groups $\left(3.5-8.1 \mathrm{mmol} / \mathrm{dm}^{3}\right)$ was also elevated in comparison with the reference values in humans $0 \pm 2.3 \mathrm{mmol} / \mathrm{dm}^{3}$ [17].

EG administration in stage I and stage II caused a rapid and statistically significant decrease in blood $\mathrm{pH}$, bicarbonate concentration and base excess since the first hours of the experiment. These changes signify the occurrence of metabolic acidosis. All the animals survived and the values of parameters under analysis began to rise to reach the reference values of the control groups at the end of the second day of the experiment. Olszowy [10] described similar results in Wistar rats in which the maximum decrease in blood $\mathrm{pH}$ and bicarbonate concentration occurred as early as 2 hours and returned in 10 hours after oral administration of EG at a dose of $3830 \mathrm{mg} / \mathrm{kg}$. Hewlett et al. [18] demonstrated the lowest bicarbonate concentration 6 hours post-dosing in Sprague-Dawley rats (EG $2000 \mathrm{mg} / \mathrm{kg}$, p.o.). Subcutaneous EG administration at a dose of $3333 \mathrm{mg} / \mathrm{kg}$ to female Sprague-Dawley rats resulted in a decrease in blood $\mathrm{pH}$ to 7.129 hours after administration [19]. More profound metabolic acidosis was described in pigtail monkeys Macaca nemestrina, which received EG at a dose of $4000 \mathrm{mg} / \mathrm{kg}$ intraperitoneally. The lowest values of blood $\mathrm{pH}$ and bicarbonate concentrations were determined $12-15$ hours post-dosing, 7.13-7.18 and 5.5-8.2 mmol/ $\mathrm{dm}^{3}$, respectively [5]. A similar bicarbonate concentration after 12 hours $\left(8.1 \mathrm{mmol} / \mathrm{dm}^{3}\right)$ was found in dogs after oral EG administration at a dose of $10740 \mathrm{mg} / \mathrm{kg}$ [9].

The time of occurrence of the most profound metabolic acidosis may be connected with the moment of peak concentration of acidic EG metabolites, mainly glycolates [1]. The authors' own studies of pharmacokinetics of EG and its metabolite revealed the maximum glycolate concentration 4 hours (stage I, $0.61 \mathrm{~g} / \mathrm{dm}^{3}$ ) and 4-6 hours (stage II, 0.68-0.75 $\mathrm{g} / \mathrm{dm}^{3}$ ) after EG administration (unpublished data). Similar maximum glycolate concentration and time of its occurrence were described by Hewlett et al. [18] after oral administration of ethylene glycol to Sprague-Dawley rats at a dose of $2000 \mathrm{mg} / \mathrm{kg}$.
The main goal of the treatment with 4-MP in acute EG poisoning is the inhibition of $A D H$, resulting in an increase in urinary EG excretion due to the inhibition of this metabolic route. Therefore, fomepizole administration should prevent the development of metabolic acidosis and multi-organ injury.

In the animals which were given single 4-MP and in combination with EG in stage I as well as they were given 4-MP 2 hours after EG administration and every consecutive 12 hours in stage II, the values of blood $\mathrm{pH}$, bicarbonate concentration and $\mathrm{BE}$ were slightly lower than the reference values in the control groups. In groups GM1 and GM2 all the acid-base balance parameters under analysis at most time points were significantly higher than the values in the untreated animals, i.e., in groups $\mathrm{G} 1$ and $\mathrm{G} 2$, which received EG only. The administration of 4-MP 2 hours after EG poisoning in group GM2 caused a statistically significant increase in blood $\mathrm{pH}$, bicarbonate concentration and $\mathrm{BE}$ as soon as 4 hours after poisoning, as compared with the untreated group $\mathrm{G} 2$ ( $\mathrm{pH} 7.33$ vs $7.20, \mathrm{HCO}_{3}{ }^{-}$ 25.9 vs $19.3 \mathrm{mmol} / \mathrm{dm}^{3}$, BE -0.6 vs $-8.9 \mathrm{mmol} / \mathrm{dm}^{3}$ ). The obtained results after simultaneous administration of EG and 4-MP (stage I) as well as after a 2-hour delay in 4-MP administration (stage II) proved 4-MP to be efficacious and rapid in preventing the development of metabolic acidosis. The therapeutic effect in stage II was achieved already after the administration of the first dose of 4-MP 2 hours after poisoning and the next maintaining doses given every 12 hours enabled the monitored parameters to recover the reference values after 24 hours of the experiment.

Similar results were reported in a study on dogs (EG $10740 \mathrm{mg} / \mathrm{kg}$, p.o.). Fomepizole administration in one dose of $20 \mathrm{mg} / \mathrm{kg} 3$ hours after EG poisoning caused an increase in bicarbonate concentration after 6 hours to $21.9 \mathrm{mmol} / \mathrm{dm}^{3}$ vs $12.6 \mathrm{mmol} / \mathrm{dm}^{3}$ in the untreated group [9]. Connally et al. [8] demonstrated the return of blood $\mathrm{pH}$ and bicarbonate concentration to reference values after 24 and 48 hours, respectively, in cats poisoned with a lethal dose of ethylene glycol and treated with 4-MP 3 hours after EG poisoning (initial dose of $125 \mathrm{mg} / \mathrm{kg}$ and maintaining dose of $31.3 \mathrm{mg} / \mathrm{kg}$ every 12 hours). In humans poisoned with $\mathrm{EG}$, who were treated with 4-MP, blood $\mathrm{pH}$ was ranged from 7.14 to 7.34 and bicarbonate concentration was ranged from 6.8 to $17.8 \mathrm{mmol} / \mathrm{dm}^{3}$. Lower values were noted in patients with renal insufficiency [20].

In conclusion, the administration of a single dose of fomepizole at a dose of $10 \mathrm{mg} / \mathrm{kg}$ with a simultaneous administration of ethylene glycol at a dose of 
$3830 \mathrm{mg} / \mathrm{kg}$ was effective in preventing a decrease in blood $\mathrm{pH}$, bicarbonate concentration and base excess during the entire experimental period.

The administration of 4-MP 2 hours after EG poisoning $(5745 \mathrm{mg} / \mathrm{kg})$ at a loading dose of $15 \mathrm{mg} / \mathrm{kg}$ and every 12 hours at maintaining doses of $10 \mathrm{mg} / \mathrm{kg}$ resulted in rapid restoration of proper values of acidbase balance parameters.

The obtained results let us conclude that fomepizole is highly efficacious in restraining the acid-base balance disorders which are concomitant with acute ethylene glycol poisonings.

\section{Acknowledgments}

This work was supported by grant no. 2P05D 03628 from the State Committee for Scientific Research and by the statutory funds of Poznan University of Medical Sciences, Poznań, Poland.

The authors declare that there is no conflicts of interest of interest in the authorship or publication of this contribution.

\section{References}

1. Barceloux DG, Krenzelok EP, Olson K, Watson W. American Academy of Clinical Toxicology Practice guidelines on the treatment of ethylene glycol poisoning. J Toxicol Clin Toxicol. 1999;37(5):537-60.

2. Brent J. Current management of ethylene glycol poisoning. Drugs. 2001;61(7):979-88.

3. Mégarbane B, Borron SW, Baud FJ. Current recommendations for treatment of severe toxic alcohol poisonings. Intensive Care Med. 2005 Feb;31(2):189-95.

4. Puka J, Szajewski J. Ethylene glycol poisoning - an experience from treating 205 cases of acute poisoning (Polish). Pol Arch Med Wewn. 1988 Aug-Sep;80(2-3):88-98.

5. Clay KL, Murphy RC. On the metabolic acidosis of ethylene glycol intoxication. Toxicol Appl Pharmacol. 1977 Jan;39(1):39-49.

6. Jacobsen D, McMartin KE. Antidotes for methanol and ethylene glycol poisoning. J Toxicol Clin Toxicol. 1997;35(2):127-43.

7. Kraut JA, Kurtz I. Toxic alcohol ingestions: clinical features, diagnosis, and management. Clin J Am Soc Nephrol. 2008 Jan;3(1):208-25.

8. Connally HE, Thrall MA, Hamar DW. Safety and efficacy of high-dose fomepizole compared with ethanol as therapy for ethylene glycol intoxication in cats. J Vet Emerg Crit Care. 2010 Apr 1;20(2):191-206.
9. Grauer GF, Thrall MA, Henre BA, Hjelle JJ. Comparison of the effects of ethanol and 4-methylpyrazole on the pharmacokinetics and toxicity of ethylene glycol in the dog. Toxicol Lett. 1987 Feb;35(2-3):307-14.

10. Olszowy Z. Experimental investigations on the course of ethylene glycol poisoning from a medico-legal and toxicological aspect. Part 2. Chosen biochemical parameters in experimental ethylene glycol poisoning (Polish). Arch Med Sąd Krym. 2000;50(2):89-101.

11. Giermaziak H, Lutz W, Giermaziak M. Biochemical and clinical aspects of the poisoning with ethylene glycol (Polish). Pol Tyg Lek. 1995;50(1-35):812-5.

12. Kujawa A, Kostek H, Szponar J, Majewska M, Ossowska B. Extremely severe metabolic acidosis and multi-organ complications in ethylene glycol intoxication: a case study (Polish). Przegl Lek. 2011;68(8):530-2.

13. Liamis G, Milionis HJ, Elisaf M. Pharmacologically-induced metabolic acidosis: a review. Drug Saf. 2010 May 1;33(5):371-91.

14. Blakeley KR, Rinner SE, Knochel JP. Survival of ethylene glycol poisoning with profound acidemia. N Engl J Med. 1993 Feb 18;328(7):515-6.

15. Kostek H, Kujawa A, Szponar J, Danielewicz P, Majewska $M$, Drelich $G$. Is it possible to survive metabolic acidosis with $\mathrm{pH}$ measure below 6.8? A study of two cases of inedible alcohol intoxication (Polish). Przegl Lek. 2011;68(8):518-20.

16. Bey TA, Walter FG, Gibly RL, James ST, Gharahbaghian L. Survival after ethylene glycol poisoning in a patient with an arterial pH of 6.58. Vet Hum Toxicol. 2002 Jun;44(3):167-8.

17. Guzek JW. Outline human pathophysiology (Polish). $1^{\text {st }}$ ed. Warszawa: WL PZWL; 2002. p. 206-10.

18. Hewlett TP, Jacobsen D, Collins TD, McMartin KE. Ethylene glycol and glycolate kinetics in rats and dogs. Vet Hum Toxicol. 1989 Apr;31(2):116-20.

19. Carney E. An integrated perspective on developmental toxicity of ethylene glycol. Reprod Toxicol. 1994 MarApr;8(2):99-113.

20. Brent J, McMartin K, Phillips S, Burkhart KK, Donovan JW, Wells $\mathrm{M}$ et al. Fomepizole for the treatment of ethylene glycol poisoning. Methylpyrazole for Toxic Alcohols Study Group. N Engl J Med. 1999 Mar 18;340(11):832-8.

$$
\begin{array}{r}
\text { Correspondence address: } \\
\text { Jędrzej Przystanowicz } \\
\text { Department of Toxicology } \\
\text { 30 Dojazd Street } \\
\text { Poznan University of Medical Sciences } \\
\text { 60-631 Poznan, Poland } \\
\text { phone: }+48618472081 \\
\text { fax: }+48618470721 \\
\text { email: jprzyst@ump.edu.pl }
\end{array}
$$

